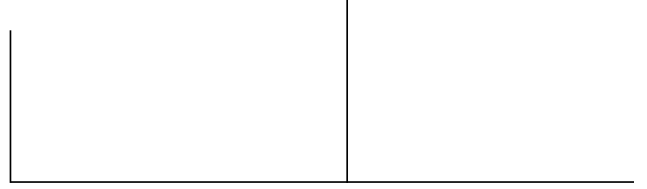

Rev. Latinoam. Psicop. Fund. VI, 1, 148-153

\title{
A teoria de John Hughlings Jackson sobre evolução e dissolução do sistema nervoso: observações clínicas, influências e repercussões
}

\section{Daniela Kurcgant e Mário Eduardo Costa Pereira}

O darwinismo e os conceitos de evolução desenvolvidos no final do século XIX influenciaram muitos neurologistas. O de maior destaque na Inglaterra foi John Hughlings Jackson (1835-1911). O desenvolvimento de uma teoria para as doenças neurológicas e mentais, baseada em especulações sobre a observação de casos de epilepsia, alterações de linguagem e de acidentes vasculares cerebrais, exerceu grande influência sobre a psiquiatria e a psicologia continental do século XIX; entretanto, por motivos ainda obscuros, houve relativamente pouca influência dessas idéias sobre a própria psiquiatria britânica. Por outro lado, os historiadores da medicina, da primeira metade do século XX, consideram determinante a contribuição de H. Jackson na concepção da denominada neurologia moderna.

Hughlings Jackson publicou cerca de 320 artigos médicos entre 1861 e 1909, nas mais importantes revistas de medicina em circulação da época, além de proferir inúmeras palestras e aulas significativas no desenvolvimento de suas teorias. Seus artigos foram reunidos e organizados posteriormente. Duas coleções de seus trabalhos foram editadas por J. Taylor. Tratam-se do Neurological Fragments of J. Hughlings Jackson (Londres, 1925) e dos Selected 
Writings of John Hughlings Jackson (Londres, 1931, 2 vols.). Em 1878, H. Jackson foi um dos co-fundadores da revista Brain, a prestigiosa publicação oficial da Sociedade de Neurologia de Londres, da qual foi editor por vários anos.

Dentre os trabalhos desenvolvidos por H. Jackson, um dos mais importantes foi "Evolution and dissolution of the nervous system", traduzido no presente número da Revista Latinoamericana de Psicopatologia Fundamental. Este baseou-se em uma de suas três palestras proferidas junto ao Royal College of Physicians of London, em março de 1884. Desta forma, o presente artigo visa expor as observações clínicas e principais idéias de H. Jackson, ilustradas pelo artigo aqui traduzido, bem como discutir a influência sobre elas das concepções evolucionistas de Herbert Spencer (1820-1903).

H. Jackson teve particular interesse pela questão da localização das epilepsias, provavelmente porque sua esposa apresentava crises parciais, também chamadas ainda hoje de crises "jacksonianas". Este tipo de epilepsia, chamada também de epilepsia unilateral, diferente das convulsões, iniciava sua manifestação em apenas uma parte do corpo.

Alguns estudiosos da época, como Brown-Séquard, professor de $\mathrm{H}$. Jackson, sugeriam que a causa da epilepsia seria a contração dos vasos sanguíneos relacionados com estruturas nervosas como a medula oblonga, ou bulbo. Tais contrações diminuiriam o aporte de sangue, o que levaria à perda da função nervosa e suscitaria a crise epiléptica.

Durante o século XIX, a idéia do espasmo sanguíneo “reflexo", como fator etiológico da epilepsia, estava relacionada com a própria teoria da ação reflexa. As fibras motoras e sensoriais da medula espinhal foram descritas por Charles Bell. Marshall Hall, por sua vez, elucidara a função reflexa da medula espinhal; ou seja, as fibras nervosas que inervam os vasos sanguíneos, por ação reflexa, causariam o espasmo sanguíneo e, assim, a crise epiléptica.

H. Jackson não excluía a teoria, então vigente, sobre a origem da chamada epilepsia unilateral, que seria deflagrada por um espasmo vascular, em ato reflexo, no nível da medula oblonga. Entretanto, Jackson observou, de forma inédita, que possivelmente alguma região do cérebro poderia estaria “doente”. Em outras palavras, propôs uma mudança na origem da epilepsia unilateral, no que diz respeito à causa e à localização desta.

A observação de casos de afasia permitiu que H. Jackson confirmasse os achados de Paul Broca, sem que conhecesse previamente tal descoberta. Na França, em 1861, Paul Broca relatou o caso de um paciente que perdera a fala após uma infecção. Depois da morte do paciente, foi realizado o exame anatomopatológico do cérebro e constatada a deterioração do terceiro giro da região frontal do hemisfério cerebral esquerdo. H. Jackson, prontamente, atribuiu a Broca o mérito da descoberta do centro motor da fala. Ele se preocupava não 
somente com a localização das doenças mas, principalmente, com as confirmações clínicas da sua teoria sobre o funcionamento do sistema nervoso.

H. Jackson procurou alcançar "generalizações racionais"; ou seja, uma lei única que explicasse simultaneamente as diferentes manifestações físicas e mentais o que, aliás, foi um pensamento dominante no final do século XIX. Para tanto, ele supunha uma hierarquia do sistema nervoso, dividindo-o em centros nervosos superiores, médios e inferiores. O próprio H. Jackson alertava para o enfoque "materialista" de suas idéias. Nas suas palavras, todos os centros nervosos, desde os mais superiores aos mais inferiores, seriam "máquinas sensório-motoras”. Os centros nervosos superiores são considerados responsáveis por funções mais numerosas, mais diferentes, mais complexas e mais especiais, enquanto que os mais inferiores têm funções opostas, ou seja, têm funções menos numerosas, mais gerais e menos complexas.

Para ele, a evolução seria um processo ascendente, com uma ordem particular, que obedeceria três regras gerais complementares. Primeiramente, a evolução seria a passagem de um nível de maior organização para um nível de menor organização, isto é, dos centros nervosos inferiores e melhor organizados, para os centros superiores e menos organizados. Em segundo lugar, a evolução seria a passagem do mais simples para o mais complexo, ou seja, de novo, dos centros nervosos inferiores para os superiores. A propósito, H. Jackson esclarece que não seria contraditório conceber centros nervosos simultaneamente mais complexos e menos organizados. Por exemplo, um centro nervoso constituído por quatro “junções” sensório-motoras é “duplamente” mais complexo que um centro nervoso constituído por duas junções. Entretanto, este último centro nervoso é mais organizado que o primeiro. Os motivos pelos quais H. Jackson considerava um centro nervoso, constituído por duas “junções” sensório-motoras, mais organizado não estão claros.

A terceira regra geral prescrevia que a evolução seria a passagem do mais automático para o mais voluntário. A conclusão proposta, levando-se em conta as três regras gerais, seria que os centros nervosos superiores poderiam ser considerados o "clímax da evolução nervosa". Justamente os centros nervosos superiores, por serem menos organizados, mais complexos e mais voluntários, constituiriam o "órgão da mente" ou, em outras palavras, a base física da consciência.

Segundo H. Jackson, a dissolução corresponderia ao processo reverso da evolução. Seria o processo mórbido, de sentido contrário ao desenvolvimento, indo do mais complexo, mais voluntário e menos organizado em direção ao mais simples, mais automático e mais organizado. Se a dissolução fosse total, o resultado seria a morte. Como a dissolução é sempre parcial, sua condição em todos os casos é "dupla”; isto é, em cada caso a dissolução corresponde a um 
elemento positivo e a um elemento negativo. Para H. Jackson, a patologia atingiria os centros nervosos de forma localizada ou uniformemente difusa. A região afetada não funcionaria adequadamente e corresponderia, portanto, ao elemento negativo do processo de dissolução. Os centros nervosos imediatamente inferiores à região afetada passam, então, a funcionar dentro de suas possibilidades de desempenho. As manifestações clínicas e mentais produzidas por esses centros nervosos "sobreviventes", corresponderiam ao elemento positivo do processo de dissolução.

Assim pensando, ele supunha que os casos de afasia, hemiplegia e epilepsia eram exemplos de dissolução do sistema nervoso que se iniciavam em diferentes centros cerebrais inferiores. A “insanidade mental”, por sua vez, teria seu processo de dissolução iniciado nos centros cerebrais mais superiores. A doença mental, isto é, a alteração patológica, causaria estados funcionais negativos, que corresponderiam a estados mentais negativos. Os sintomas mentais positivos (ilusões, alucinações, delírios e comportamentos “extravagantes”) seriam o resultado da atividade de centros nervosos mais inferiores, que não foram atingidos pelo processo patológico de dissolução. Em outras palavras, ocorre a "sobrevivência do mais forte", no que diz respeito aos centros nervosos.

Stephen Jay Gould, historiador da ciência, alerta para o fato de que a expressão "sobrevivência do mais forte" foi cunhada pelo pensador inglês Herbert Spencer (1820-1903), não por Charles Darwin, como comumente se pensa. As próprias concepções de evolução e dissolução, que corresponderiam aos estados saudáveis e patológicos, aplicadas por H. Jackson, foram marcadamente influenciadas pelo pensamento de H. Spencer. Nos seus trabalhos, por exemplo, H. Jackson citou trinta e oito vezes trechos da coletânea The Principles of Psychology, de H. Spencer.

Sem termos a pretensão de esgotar o assunto, cabe ressaltar que $\mathrm{H}$. Spencer desenvolveu idéias sobre a evolução não necessariamente em consonância ao pensamento de C. Darwin. Aliás, coube a H. Spencer estender o uso das idéias evolucionistas ao campo da sociologia, após a passagem pela biologia e psicologia.

O filósofo da ciência Georges Canguilhem sugere que o "evolucionismo" caracterizou uma certa ideologia científica no século XIX. H. Spencer acreditou poder formular uma lei mecânica do progresso universal regulando universalmente a formação do sistema solar, das espécies vivas, do homem, da sociedade e da linguagem.

Os princípios de embriologia de Karl-Ernst von Baer e a publicação de $A$ origem das espécies por C. Darwin deram ensejo à criação, por H. Spencer, a este sistema de evolução generalizada, que tivesse um caráter científico, e que legitimasse, no sentido político, a separação entre indivíduo e Estado, como parte de uma proposta liberal. A ideologia evolucionista, segundo G. Canguilhem, 
serviria para justificar os interesses da sociedade industrial, em conflito com a sociedade Vitoriana tradicional, por um lado e, por outro, com a miséria e a injustiça social. Neste sentido, G. Canguilhem retoma o conceito marxista de ideologia, considerando-a como a representação da realidade natural ou social, cuja verdade não reside no que esta representa, mas no que cala.

Segundo a proposta de G. Canguilhem, o contexto histórico-social sombrio da época é ofuscado pela ênfase na lei do progresso universal proposta, entre outros, por $\mathrm{H}$. Spencer e que, possivelmente, serviu de pano de fundo para o desenvolvimento de outros pensamentos e estudos. Em vista dessas circunstâncias, não surpreende o intercâmbio havido entre Herbert Spencer e John H. Jackson.

Apesar da influência marcante dos estudos de H. Spencer sobre as idéias de H. Jackson, sua importância é minimizada não somente por estudiosos da História da Medicina, mas também por filósofos e historiadores da ciência. Para muitos, o pensamento de $\mathrm{H}$. Spencer é considerado "menor” ou obsoleto. O risco de se desconsiderar a influência de H. Spencer no pensamento de H. Jackson é o de não se poder contextualizar devidamente as concepções de H. Jackson sobre o sistema nervoso, bem como as origens da neurologia moderna.

Sigmund Freud foi o primeiro estudioso a reconhecer a importância dos trabalhos de H. Jackson, em uma época que passavam desapercebidos. Em 1891, S. Freud utilizou a concepção hierárquica de sistema nervoso, proposta por $\mathrm{H}$. Jackson, em seu livro de neurologia sobre a afasia.

Segundo G. Berrios, o modelo de funcionamento do sistema nervoso proposto por $\mathrm{H}$. Jackson permitiu uma liberdade de entendimentos frente às restrições conceituais, o que o tornou plausível e instigante. Estas características podem ser comprovadas nos traços “jacksonianos" encontrados nos estudos de T. Ribot, P. Janet, T. Meynert, G. de Clérambault, H. Ey - que qualificava sua teoria como neojacksionista, além do já mencionado S. Freud. O interesse não se baseia em uma alusão à verdade científica, mas na habilidade deste modelo em permitir múltiplas narrativas sobre o funcionamento cerebral. Contemporaneamente, as idéias de H. Jackson têm influenciado pesquisas sobre modelos neuropsicológicos das funções cognitivas, particularmente a consciência e a memória.

\section{Referências}

Berrios, German \& Porter, Roy. A History of Clinical Psychiatry. Londres/New Brunwick (New Jersey): Athlone Press, 1995.

Broadbent, William. Hughlings Jackson as pioneer in Nervous Physiology and Pathology. Brain, n. 26, p. 305-66, 1903. 
Canguilhem, George. Ideologia e racionalidade nas ciências da vida. Trad. portuguesa de Emília Piedade. Lisboa: Edições 70, 1977.

Engelhardt, H. Tristram. John Hughlings Jackson and the Mind-Body Relation. Bulletin of the History of Medicine, v. 49, n. 2, p. 137-51, 1975.

Ey, H. Des idées de Jackson à um modèle organo-dynamique em psychiatrie. Toulouse: Privat, 1975.

Freeman, Derek. The evolutionary theories of Charles Darwin and Herbert Spencer. Current Anthropology, v. 15, n. 3, p. 211-37, 1974.

Gould, Stephen Jay. A tale of two worksites. Natural History, n. 106, p. 18-22, 29, 6268, 1997.

GREENBATT, Samuel H. The major influences on the early life and work of John Hughlings Jackson. Bulletin of the History of Medicine, n. 39, p. 346-76, 1965.

KURCGANT, Daniela. A influência de Herbert Spencer (1820-1903) na concepção de John Hughlings Jackson (1835-1911) sobre o sistema nervoso e a epilepsia. Tese de mestrado. São Paulo, Pontifícia Universidade Católica de São Paulo, 2002.

Langworthy, Orthelo R. Hughlings Jackson - His opinions concerning epilepsy. Journal of Nervous and Mental Disease, n. 76, p. 574-85, 1932.

Oppenneim, Janet. Shattered Nerves: Doctors, Patients, and Depression in Victorian England. Nova Iorque/Oxford: Oxford University Press, 1991.

Richards, Robert J. Darwin and the Emergence of Evolutionary Theories of Mind and Behavior. Chicago/Londres: The University of Chicago Press, 1987.

RIESE, Walther. The sources of jacksonian neurology. Journal of Nervous and Mental Diseases, n. 124, p. 125-34, 1956.

Sмітн, C. U. M. Evolution and the problem of mind. Part I: Herbert Spencer. Journal of the History of Biology, v. 15, n. 1, p. 55-88, 1982.

Evolution and the problem of mind. Part II: John Hughlings Jackson. Journal of the History of Biology, v. 15, n. 2, p. 241-62, 1982.

SPENCER, Herbert. The Principles of Biology. Londres/Edimburgo: Williams and Norgate, 1899, 2 vols.

The Principles of Psychology. 4. ed. Londres/Edimburgo: Williams and Norgate, 1899, 2 vols.

Stone, Michael H. Healing the Mind: A History of Psychiatry from Antiquity to the Present. Nova Iorque/Londres: W.W. Norton \& Company, 1997.

TAYLOR, James (Org.). Selected Writings of John Hughlings Jackson. Londres: Hodder and Stoughton, 1932.

Temkin, Owsei. The Falling Sickness: A History of Epilepsy from the Greeks to the Beginnings of Modern Neurology. 2. ed. Baltimore/Londres: The Johns Hopkins University Press, 1994. 